\title{
Intensity of Off-Farm Employment and Its Impact on Wage Distribution: Does the Source of Health Insurance Coverage Matter?*
}

\author{
Hisham S. El-Osta \\ Agricultural Economist with the Economic Research Service, United States Department of Agriculture, Washington DC, USA \\ Email: helosta@ers.usda.gov
}

How to cite this paper: El-Osta, H.S. (2017) Intensity of Off-Farm Employment and Its Impact on Wage Distribution: Does the Source of Health Insurance Coverage Matter? Theoretical Economics Letters, 7, 1713-1734.

https://doi.org/10.4236/tel.2017.76116

Received: August 4, 2017

Accepted: October 15, 2017

Published: October 18, 2017

Copyright $\odot 2017$ by author and Scientific Research Publishing Inc. This work is licensed under the Creative Commons Attribution International License (CC BY 4.0).

http://creativecommons.org/licenses/by/4.0/

\begin{abstract}
The determinants of off-farm wages, with emphasis on the role of working "full-time" off the farm, are examined using data from the 2015 Agricultural Resource Management Survey and quantile regression. The targeted groups of farm operators for the analysis are based on whether health insurance coverage is obtained from the "off-farm" employer, and whether it is obtained from "other" sources. Findings indicate a negative association between "full-time" off-farm work and off-farm wages among farm operators in both categories who are at the higher portions of their respective off-farm wage distributions, which is in accordance with the compensating differential prediction.
\end{abstract}

\section{Keywords}

Agricultural Resource Management Survey, Off-Farm Wage Gap, Full-Time Work, Health Insurance Coverage, Quantile Regression, Semi-Nonparametric Regression

\section{Introduction}

A characteristic of American agriculture is its widely-recognized shift in the structure of farming towards larger and more profitable farms due to scale economies coupled with technological change. ${ }^{1}$ A consequence of this continuing change, which started nearly six decades ago, is that a larger share of farm output is produced on smaller share of farms [2]. Additionally, the shift over the ${ }^{\star}$ The views expressed are those of the author and should not be attributed to the Economic Research Service or USDA.

${ }^{1}$ For example, a study by [1] showed that between 1991 and 2009, agricultural production shifted to larger farms. In 1991, family farms with production of more than $\$ 1$ million accounted for 21 percent of total production. By 2009, this sales class accounted for 39 percent of farm production. The same study documents over the same time period, using median rate of return on equity, the higher profitability of these larger farms compared to farms in smaller sales categories. 
last few decades in the labor allocation decisions of farm operators in favor of off-farm activities has provided a critical income source to a majority of U.S. farm households (see [3]). For example, in the early 1980s, about sixty percent of the total income of farming households, on average, originated from off-farm sources; a level that stands now at about eighty percent, which is also about six times greater than cash farm income levels [4] and [5].

Based on data from the 2015 Agricultural Resource Management Survey (ARMS), about half of all U.S. farm households in the lower forty-eight states have their operators working off-farm, with nearly 70 percent of these farmers working in full-time jobs. ${ }^{2}$ Research by [8] shows a positive association between the variability in farm income and the incidence of off-farm work by farm operators. The research also asserts the contributing role of off farm income in managing risk through diversification in agricultural production. The closing of the income gap between farm and non-farm households since 1998 has also been attributed to the growth in the earnings from off-farm sources resulting primarily from greater returns to farm household skills employed off the farm [9]. The fact that nearly 80 percent of total household income originates from off-farm sources, with income from off-farm wages and salaries being the major contributor, demonstrates the importance of these sources of income to the economic well-being of the household.

Data from the 1981 U.S. Department of Agriculture Family Farm Survey showed that sixty percent of the operators who worked off the farm had reported full-time wage and/or salary jobs [10]. The statistics further showed that farmers with full-time off-farm employment, those working in durable goods manufacturing, and those that were paid higher wage rates were most likely to receive fringe benefits that included, singly or in combination, paid vacation and/or sick leave, health insurance, private pension plans, and life insurance. Using data from the 1997-2004 National Health Interview Survey, [11] noted that fifty percent of individuals in farm families have employer-provided health insurance coverage.

The theory of equalizing differences as proposed by [12] points to observed wage differentials that are necessary to equalize the total monetary and nonmonetary advantages or disadvantages among work activities and among workers themselves. As part of the measurable job attributes noted by [12] on which compensating wage differentials have been shown to arise empirically, and that are relevant to farm households with an operator working off the farm full-time and who receive an employer-sponsored health insurance coverage, is the composition of pay packages, which includes vacations, pensions, and other fringe benefits as substitutes for direct cash wage payments.

Recent research by [13] noted that the Affordable Care Act (ACA), which was

\footnotetext{
${ }^{2}$ As in [6], this paper defines a farm operator with a full-time off-farm employment as one who works 35 hours or more per week (or 1820 hours annually) in an off-farm business or an off-farm wage and/or salary job. This amount of work hours that separates full-time off-farm employment from part-time employment is consistent with the Bureau of Labor Statistics definition of part-versus full-time work status; a definition that has been in effect since 1947 [7].
} 
signed into law on March 23, 2010, has implications for the source of health insurance coverage for farm operator households and possibly for how much of their time they allocate to off-farm employment. The ACA requires employers with at least 50 full-time-equivalent employees to offer "affordable" health insurance to employees working 30 or more hours per week. This requirement of the ACA may have implications on both the levels of offered weekly work hours by employers in the off-farm labor markets and on off-farm hourly-wages, particularly for the young and low educated individuals [14].

Considering the importance of the income from off-farm wages and/or salaries and/or off-farm business to the wellbeing of farm households, and of the employer-provided health insurance, the need to examine how a labor allocation decision by the farm operator that heavily favors off-farm employment may impact the per-hour off-farm earning capacity of the farm operator becomes evident. ${ }^{3}$ The specific objective of this study is to investigate, in accordance with the theory of equalizing differences as proposed by Rosen [12], if there is a difference in the effect of working full-time off the farm on the hourly off-farm wage rates among two diverse groups of farm operators; those who have employer-provided health insurance coverage, and those who obtain health insurance coverage from "other" sources. ${ }^{4}$ To allow for the discernment of impact of full-time work at various locations of the distribution of wage rates and not just at the "mean", the paper utilizes a conditional quantile regression developed by [16].

\section{Literature Review}

A general view among economists is that an employer seeking to maximize profit would react to costs associated with the provision of health insurance coverage by lowering wages, an action which is undertaken to ensure the maintenance of the total reward package paid to employees. Despite such a stipulated inverse relationship between wages and health insurance benefits, existing research on the subject continues to be mixed where some studies point to evidence in support of the theory of compensating differential originated by [12], while others stand in opposition or find evidence of a trivial impact.

Early research by [17] found, based on multivariate analysis and data from the 1974 Rand Health Insurance Experiment, a positive, albeit statistically insignificant association between wages and employer-paid total health insurance premiums even after controlling for worker characteristics. Using a hedonic wage

\footnotetext{
${ }^{3}$ A study by Riportella and O'Neil [15] notes that under the ACA, members of farm families no longer need to work off-farm just for the purpose to secure affordable health insurance. Furthermore, since only income and family size are considered under the ACA, even farm families with high net worth (land, buildings, equipment, etc.) can qualify for health insurance through expanded Medicaid because the ACA does not include an "asset test" for eligibility nor for premium tax credits.

${ }^{4}$ Other sources of health insurance coverage include a direct purchase of private policy by or for the household, the farming operation associated with the farm household, or Medicare, Medicaid, or other public insurance.
} 
model and 1980 panel data from the Census Bureau's Current Population Survey, [18] found a similarly positive, yet statistically insignificant association between wages of railway workers and employer-sponsored health insurance coverage. Lehrer and Pereira [19] used 1984-2000 CPS data to examine the labor market experience of displaced workers who change jobs for arguably exogenous reasons. The potential impact of an employer's health insurance provision on wages was examined using a panel regression estimator in addition to wage gap decomposition techniques. While findings indicated a positive association, though statistically insignificant, between health insurance and a worker's wage thereby negating any evidence of a compensating wage differential, the study however showed that employer-sponsored coverage is increasingly affecting the dispersion of wages across employment sectors. Results also suggested that there have been substantial changes in how displaced workers sort to firms that offer health insurance benefits over the past two decades. Monheit, Hagan, Berk, and Farley [20], based on cross-sectional data from the 1977 National Medical Care Expenditure Survey, found higher wages among those employees with employerprovided coverage in contrast to those without coverage.

A paper by [21] reviewed an extensive and diverse body of empirical studies that emerged in prior years to assess the impact of health insurance on the labor market, with the summary of evidence showing that employees, as a group, ultimately bear the costs of any payments an employer makes for health insurance. Olson [22] used health insurance coverage from the 1990-1993 CPS along with two-stage lease squares estimation to discern the impact of employer-provided health insurance on wages of married women with full-time employment. Findings indicated, in contrast to a number of earlier studies, a $20 \%$ discount in wages resulting from health insurance coverage. Goldman, Sood, and Leibowitz [23] examined information for employees under age 65 at a single U.S. firm in addition to information on employee compensation decisions during a three-year period (1989-1991) when health insurance premiums were rising rapidly. Findings suggested that about two-thirds of the increase in health insurance premium was financed out of cash wages and the remaining one-third was financed by a reduction in benefits.

\section{Data}

The primary data source for this study is the 2015 ARMS. The ARMS, which has a multistage stratified random sampling design, is conducted annually in the lower 48 states by the National Agricultural Statistics Service (NASS) and the Economic Research Service (ERS). Auxiliary data on the 2015 local area unemployment statistics are from the Bureau of Labor Statistics files (U.S. Department of Labor). ${ }^{5}$

The size of the initial probability-based ARMS sample in 2015 was 16,683 ,

${ }^{5}$ Climate data were provided by Ryan Williams, Economic Research Service, U.S. Department of Agriculture. 
which represented a population of 2,031,660 farms using survey weights. Farms where the age of the farm operator was 65 or older were deleted from this sample because of health insurance eligibility through Medicare. Nearly all persons who are 65 or older tend to enroll in the Medicare health insurance program that is administered by the U.S. government [24]. Exclusion of farms with older farm operators is consistent with earlier research that examined the impact of sources of health insurance coverage on farm operators' labor allocation decisions and/or healthcare expenditures by farm operator households [24].

Additionally, in computing the hourly off-farm wage rate of the working farm operator within this sub-sample, a number of outliers were detected which were likely due to measurement error. ${ }^{6}$ To mitigate the ill-effect of these outlying observations, as in [25], the upper $1 \%$ of the weighted observations of the off-farm income and the off-farm worked hours needed in the computation of off-farm wage rates were trimmed. ${ }^{7}$ Accordingly, the number of observations in the final sub-sample was 10,796, which represents, based on survey weights, a total of $1,257,076$ of these farm operator households. The farms of these nearly 1.26 million households accounted for 62 percent of the 2.03 million farms represented in the 2015 ARMS and produced 77 percent of the total farm output.

\section{Methodology}

\section{Assessing the Impact of Full-Time Work on Wages}

A variant of the human capital earnings model developed by [27] is used to determine the impact of working full-time off the farm on the differentials in the hourly off-farm wages among farm operators based on the source of their health insurance coverage (see also [5] and [28]). Specifically, the aim of the earning model is to first estimate the effects of a set $\dot{X}$ comprised of an indicator of full-time work off the farm, of personal characteristics, and of other determinants describing the amenities and the macroeconomic conditions of the local labor markets on off-farm wages. Rather than using classical linear regression which estimates a conditional mean function of off-farm wages, a conditional quantile regression denoted by $Q_{\tau}($.$) , as originally proposed by [16], is esti-$ mated for all portions of the probability distribution of the outcome variable:

$$
\begin{aligned}
& Q_{\tau}\left(\ln W_{w, j i} \mid \dot{X}_{j i}\right)=Q_{\tau}\left(Y_{j i} \mid \dot{X}_{j i}\right)=X_{j i}^{\prime} \beta_{j}+\beta_{j, K+1} x_{j i}+\varepsilon_{j i}, \\
& \text { where } \tau=\int_{-\infty}^{\dot{X}_{j i}^{\prime} \dot{\beta}_{\tau}} f_{Y_{j i}}(y \mid \dot{X}) \mathrm{d} y \\
& \text { and } x_{j i}=\left\{\begin{array}{ll}
1, & x_{j i}^{*}>0 \\
0, & x_{j i}^{*} \leq 0
\end{array}, \quad i \in\{1, \cdots, n\}, j \in\{e, o\} .\right.
\end{aligned}
$$

In Equation (1), $\ln \left(W_{w, j i}\right)$ is the natural logarithm of hourly off-farm wage

\footnotetext{
${ }^{6}$ Hourly wage rate was estimated by dividing the income received by the farm operator in 2015 from the sum of off-farm wages and/or salaries and/or an off-farm business by the sum of their corresponding total off-farm work hours.

${ }^{7}$ See also [26] where trimming of observations was done at the highest and lowest percentiles of the distribution.
} 
of the $i^{\text {th }}$ farm operator where health insurance coverage is obtained from the operator's off-farm "employer" $(j=e)$ or from "other" sources $(j=o)$, and the random variable $Y$ is characterized by its off-farm wage distribution function $F\left(y_{i}\right)=\operatorname{Prob}\left(Y \leq y_{i}\right)$. Also, $X$ is a vector of $K$ exogenous explanatory variables, $x_{j i}^{*}$ is an unobserved latent variable capturing the decision of the farm operator to work full-time off the farm, $\varepsilon_{j i}$ is a random disturbance term, and $f_{Y_{i j}}($.) is the probability density function of $Y$. The quantile regression estimates in $\beta_{\tau}$ are interpreted as the expected rates of return to farm operator characteristics at the $\tau^{\text {th }}$ quantile of the conditional wage distribution from the $j^{\text {th }}$ health insurance source.

\section{Methodological Issues}

\subsection{Sample Selection Bias}

A potential source of misspecification in the estimation of Equation (1) is due to sample selection bias, an issue that is relevant only to the regression model where health insurance coverage by a farm operator is obtained from a source 'other' than from an off-farm employer $(j=o)$. Specifically, selection bias arises since the endogenous off-farm wage $Y_{o i}$ is observed only when the operator in this category self-selects to participate in off-farm employment. The off-farm labor participation decision undertaken by the farmer is not random and is potentially correlated with unobserved characteristics such as, among others, ability, motivation, preferences, and risk tolerance.

Heckman [29] notes, among others (e.g., [30]), that sample selection bias, which results in inconsistent parameter estimates, is a missing variable problem, and to mitigate the bias effectively, a sample correction term would need to be included when implementing a mean regression in the estimation of an outcome variable such as $Y_{i}$. Studies by Buchinsky [31] and [32] note that since the bias term is of unknown form when quantile regression rather than mean regression is used, implementation of the traditional two-step self-selection correction procedure with its assumption that the errors have a normal distribution as proposed by [29] becomes problematic. This paper corrects for self-selection by implementing a two-step semiparametric regression method following the threshold crossing model as delineated in [32].

The procedure, which seeks for identification and for a consistent estimation of the regression parameters, starts by first specifying the wage offer equation which depends linearly on a set of operator and labor market characteristics as in:

$$
Y_{o i}^{*}=X_{o i}^{\prime} \beta_{o}+\varepsilon_{1, o i}, \quad i \in\{1, \cdots, n\}
$$

where $Y_{o i}^{*}$ is observed only if it exceeds the operator's reservation wage $Y_{o i}$, which is represented by:

$$
Y_{o i}^{r}=g_{o, r}\left(Z_{o i} ; \alpha_{o}\right)+\varepsilon_{2, o i}, \quad i \in\{1, \cdots, n, n+1, \cdots, q\}
$$


Next, Equation (2) can be written in the context of quantile regression and without the $\mathrm{i}^{\text {th }}$ subscript as:

$$
Y_{\tau}^{*}=X^{\prime} \beta_{\tau}+\varepsilon_{1, \tau}, \quad 0 \leq \tau \leq 1
$$

Consistent with the representation in [31] and [32], the observed hourly off-farm wages for farm operators who obtain their health insurance coverage from sources 'other' than from off-farm employers can be modeled as:

$$
Y=d^{*}\left(X^{\prime} \beta_{\tau}+\varepsilon_{1, \tau}\right),
$$

where $d=I\left(Y^{*}>Y^{r}\right)$ and $I$ is the customary indicator function that returns 1 when its argument is true and 0 when its argument is false.

The conditional quantile of the observed off-farm wages when sample selection occurs is given by:

$$
Q_{\tau}(Y \mid X)=X^{\prime} \beta_{\tau}+Q_{\tau}\left(\varepsilon_{1, \tau} \mid X, d=1\right)=X^{\prime} \beta_{\tau}+\eta_{\tau},
$$

where $\eta_{\tau}$ is the sample selection correction function with an unknown distribution.

Following the argument in [31], if $Q_{\tau}\left(\varepsilon_{1, \tau} \mid X, d=1\right)$ is a function of only a single index $g$ (see [33]), then the estimation of the probability of participation in off-farm work with a latent regression error $\varepsilon$ can be described in the following:

$$
\begin{aligned}
\operatorname{Pr}(d=1 \mid Z) & =\operatorname{Pr}\left(Y^{*}>Y^{r} \mid Z\right)=\operatorname{Pr}\left(X^{\prime} \beta_{\tau}+\varepsilon_{1, \tau}>Z^{\prime} \alpha+\varepsilon_{2}\right) \\
& =\operatorname{Pr}\left(\varepsilon_{2}-\varepsilon_{1}<X^{\prime} \beta_{\tau}-Z^{\prime} \alpha\right)=g_{\varepsilon}(S, \gamma), \quad \varepsilon=\varepsilon_{2}-\varepsilon_{1}
\end{aligned}
$$

where $g_{\varepsilon}\left(S^{\prime} \gamma\right)$ is a function of characteristics in vector $S$ that include, in addition to those in $X$, some additional exogenous "exclusion restriction" variables (i.e., $X \subset S){ }^{8}$

Since both the offered and the reservation wages depend partly on unobserved individual attributes, ([31]; p. 4) imposes a condition that the joint bivariate density $\omega \equiv\left(\varepsilon_{1}, \varepsilon_{2}\right)$ is continuous (i.e., $\omega \in \Omega \subset \mathfrak{R}^{n}$ where $\Omega$ is a continuous sample space) in addition to the requirement that it depends on $S$ (i.e., $f_{\omega}(. \mid S)=f_{\omega}(. \mid g(S, \gamma))$. Considering the fact that the form of the sample-selection function $\eta_{\tau}$ in Equation (6) is unknown, [31] approximates this correction term using a series expansion. The process of estimating the hourly off-farm wages in Equation (6) follows the two-step procedure similar to one introduced originally by [29]. Specifically, the first step utilizes a semiparametric maximum likelihood based regression to estimate the selection parameters $\gamma$ based on Equation (7).

This method, which henceforth will be referred to as semi-nonparametric (SNP) estimator, uses a flexible functional approximation of the distribution of the latent regression errors by relaxing the restrictive standardized Gaussian distributional assumption imposed by the probit regression, and by letting the data identify the distribution of the errors under the independence assumption [34]. ${ }^{8}$ Note that the only variable excluded from the vector $S$ is the indicator variable $x_{i j}$ that denotes whether or not the operator works "full-time" off the farm. 
This estimator, as originally proposed by [35] and later generalized by [36], starts by approximating the unknown m-variate density function $f\left(\varepsilon_{1}, \varepsilon_{2}, \cdots, \varepsilon_{m}\right)$ by a Hermite polynomial expansion, $h(\varepsilon) .{ }^{9}$ Specifically, the approximation process centers on probability densities of the following Hermite form (see [37]):

$$
h^{*}(\varepsilon)=\frac{1}{\psi_{M}} \alpha_{M}^{2}(\varepsilon) \phi^{2}(\varepsilon \mid \Sigma),
$$

where $h(\varepsilon) \subset H_{M}, \alpha_{M}$ is a polynomial of order $M$ [i.e., $\left.\alpha_{M}=\left(\alpha_{0}, \alpha_{1}, \cdots, \alpha_{M}\right)^{\prime} \in \mathfrak{R}^{M+1}, \alpha_{0}=1\right], \psi_{M}$ is a normalization factor that ensures $h^{*}$ integrates to a value of one, and $\phi$ is the multivariate standard normal probability density function, also known in the literature as the "base" density, with mean 0 and covariance matrix $\Sigma$.

For the bivariate density case, a parameterization of Equation (8) is represented by the following squared polynomial series expansion: ${ }^{10}$

$$
\begin{aligned}
h^{*}\left(\varepsilon_{1}, \varepsilon_{2}\right) & =\frac{1}{\psi_{M}}\left(\alpha_{M}\left(\varepsilon_{1}, \varepsilon_{2}\right)\right)^{2} \phi\left(\varepsilon_{1}\right) \phi\left(\varepsilon_{2}\right) \\
& =\frac{1}{\psi_{M}}\left(\alpha_{M} \sum_{a, b=0}^{M} \alpha_{a b} \varepsilon_{1}^{a} \varepsilon_{2}^{b}\right)^{2} \phi\left(\varepsilon_{1}\right) \phi\left(\varepsilon_{2}\right)
\end{aligned}
$$

where $\psi_{M}=\iint \alpha_{M}\left(\varepsilon_{1}, \varepsilon_{2}\right)^{2} \phi\left(\varepsilon_{1}\right) \phi\left(\varepsilon_{2}\right) \mathrm{d} \varepsilon_{1} \mathrm{~d} \varepsilon_{2}$.

Next, the flexible functional approximation of the density in Equation (9) is used in constructing a pseudo log-likelihood objective function which provides the basis in the estimation of the regression in Equation (7). However, construction of a likelihood function in addition to achieving consistent estimation of model's parameters is possible only if $\mathrm{M}$ in (8) is explicitly allowed to increase with sample size (see [34] [36]).

The second step thus involves running quantile regression as in Equation (6) on $\mathrm{X}$ and on estimates of $\eta_{\tau}(g)$ which are represented by the following estimated expansion power series (see [38] [39]):

$$
\hat{\eta}_{\tau}(g)=\sum_{k=1}^{K}\left[\lambda\left(S^{\prime} \hat{\gamma}\right)\right]^{k}, K \rightarrow \text { infinity }
$$

where $\lambda($.$) is proportional to the customary inverse Mills ratio (IMR), and$ where $K$ is allowed to grow with sample size.

\subsection{Endogeneity Bias}

Another econometric concern relates to unobserved characteristics among farm operators captured in the error term in (1) that are correlated with the decision by the farmer to work full-time off the farm (e.g., superior ability, health status, risk tolerance, etc.) and with observed determinants (e.g., experience) of off${ }^{9}$ The Hermite polynomials, which form the derivatives of $C D F$, can be computed by a recursive process where the sequence of terms is as follows: first term is $h_{0}(\varepsilon)=1$, second term $h_{1}(\varepsilon)=\varepsilon$, third term $h_{2}(\varepsilon)=\varepsilon^{2}-1$, the next term $h_{3}(\varepsilon)=\varepsilon^{3}-3 \varepsilon$, and so on.

${ }^{10}$ While in (9) the normal density is used as the base for $H_{M}$ as part of the approximation of the unknown density, and as noted by [37], this is not necessary as any probability density of a random variable with a moment generating function could be used instead. 
farm wages. The resulting endogeneity in (1) due to the omission of the individual-specific heterogeneity from the model hence has the potential to induce bias in the estimation of the impact of full-time, off-farm work status. Many studies (e.g., [40]), for example, have noted that if workers with higher ability have stronger labor market attachment than lower ability workers, then results of regression estimates are likely to be "upwardly biased".

To test and to account for the possibility that $x_{j i}$ is endogenous, a two-step instrumental variables $(I V)$ estimation procedure as proposed by [41] was implemented. The first step estimates the propensity of the farm household to participate in the off-farm labor market on a "full-time" basis as described in Equation (1) by the latent index $x_{j i}^{*}$ using a probit regression model and a set of strictly exogenous variables as described in a vector $z_{j i}$. Estimation of the probit model, which includes a set of $m$ "exclusion restriction" variables that are needed for model's identification, results in the estimated parameters $\hat{\zeta}^{\prime}$, the standard cumulative distribution function $\Phi($.$) , and the probability density function of$ the standard normal $\varphi(.) .{ }^{11}$ In addition, the estimation allows for the construction of the generalized residuals $v_{j i}$ which is fitting for a large class of non-linear econometric models including the probit model (see [30] [42]):

$$
\hat{v}_{\tau}=\left(x_{j i}-\Phi\left(\hat{\zeta} z_{j i}\right)\right) \varphi\left(\hat{\zeta}^{\prime} z_{j i}\right)\left(1-\Phi\left(\hat{\zeta}^{\prime} z_{j i}\right)\right)^{-1}
$$

The second step involves estimating the $f^{\text {th }}(j=e, o)$ off-farm wage model using the regression models in Equation (1) with both $x_{j i}$ and $\hat{v}_{j i}$ included. A $t$-test of the hypothesis that the coefficient of $\hat{v}_{j i}$ equals zero is a statistical test of the exogeneity of $x_{j i}$ (see [41]), and failure to include $\hat{v}_{j i}$ in Equation (1) based on a rejection of this hypothesis will yield inconsistent and biased parameter estimates. This two-stage residual inclusion method to attend to endogeneity concerns thus allows for estimates in the off-farm wage regression models to be consistent [43].

\subsection{Heteroscedasticity Bias}

A final issue of concern is the potential presence of heteroscedasticity in the model, which is not surprising due to the cross-sectional nature of the ARMS data. As a remedy, the analysis, in addition to employing quantile regression to addresses this problem, uses either bootstrapping or the Huber-White sandwich robust variance estimator (See [44]). A benefit of using these two type of variance estimators in this study is the fact that the ARMS data has a complex sur-

\footnotetext{
${ }^{11}$ The set of $m_{j}$ "exclusion restriction" variables used in the "full-time" off-farm work probit regression when health insurance coverage is obtained from "other" sources (i.e., when $j=$ " $o$ ") are: farm operator annual on-farm work hours, and size of the household $(H H S)$ of farm operator along with its quadratic term. Correspondingly, the variables used when health insurance coverage is obtained from operator's "off-farm" employer (i.e., when $j=$ " $e$ ") are: farm household size, farm operator off-farm labor participation in previous year ( $=1 ; 0$ otherwise), and gross value of farm sales (GVS) in previous year $(\$ 10,000)$ in addition to quadratic and cubic terms of GVS. Each of the two sets of "exclusion restriction" variables used in each of their respective models are used since they proved to be strong predictors of $x_{j i}$ and not correlated with off-farm wages.
} 
vey design which would have required the use of the Jackknife variance estimation method (see [45]) had the ARMS dataset been utilized in full rather than as a subset (i.e., a subset that excluded, among others, the operators aged 65 years or older).

\section{Results}

Summary statistics and definitions of the variables used in the estimation of the sample-selection equation for the group of farm operators with provision of health care from sources 'other' than from an off-farm employment are presented in Table 1 . The table also shows analogous information for the variables used in the estimation of off-farm wages by source of health insurance coverage.

The estimation of the off-farm labor participation model using the single index estimator described above (see [36] [46]) is based on a sample size of 8595 , which represents nearly 0.84 million farm operators. About a third of these operators worked off the farm in 2015. On average, farm operators in this group where health insurance coverage is purchased from sources "other" than from an off-farm employer have 33.5 years of potential work experience. ${ }^{12}$ In addition, the majority of these farm operators are white, and have high school education. In the lower portion of Table 1, the weighted average of the per-hour off-farm wages for those operators with health insurance coverage acquired from an "off-farm" employer in 2015 was significantly higher ( $p$-value $=0.05$ ) than its corresponding average for those operators with coverage obtained from "other" sources, at about $\$ 37.00$ compared to nearly $\$ 33.00$, respectively.

The top panel of Figure 1 presents the estimated kernel densities of the log off-farm wage rates for farm operators by their source of health insurance coverage. As evident from these plots which show "non-symmetrical" and "leftward-skewed" distributions, the estimated density of off-farm wages for those operators whose insurance is purchased from the "employer" falls primarily above and to the right side of the density of wages of those whose health insurance coverage is obtained from "other" sources, which indicates a more favorable hourly off-farm wage distribution. ${ }^{13}$ The lower panel of Figure 1 shows the empirical cumulative

\footnotetext{
${ }^{12}$ The potential experience which refers to any type of work is defined as maximum $(0$, age of operator-6 years in school) (see [47] [48]). To facilitate the construction of this variable, and since the ARMS collects the information on the education variable in a discrete form (e.g., 1 = Less than high school diploma, 2 = High school, 3 = Some college, and $4=$ College graduate and beyond), another proxy variable for education is computed by assigning a level of education for each of these discrete categories (e.g., Less than high school diploma $=10$ years, High school $=12$ years, Some college $=14$ years, and College graduate and beyond $=17$ years).

${ }^{13}$ The estimated skewness coefficients for the off-farm wage distributions in the " $o$ " and " $e$ " categories are -0.84 and -0.16 , respectively. The kurtosis values for these distributions are significantly larger than zero (5.35 and 5.21, respectively), which indicate sharper peaks and heavier tails than a normal distribution would have shown. Moreover, results of Shapiro-Francia tests with values of $W$ statistic of 0.95 and 0.98 ( $p$-value $=0.00$ ) for the log off-farm wage distributions in " $o$ " and " $e$ " categories rejected the null hypothesis that off-farm wages are normally distributed. Performing a Kolmogorov-Smirnov test based on these two empirical distribution functions resulted in a combined $D$ statistic of 0.2006 ( $p$-value $=0.00)$ which allows for the rejection of the null hypothesis that the hourly off-farm wage rate distributions by insurance coverage status are equal.
} 
Table 1. Summary statistics of variables used in the weighted regression models: 2015.

\begin{tabular}{|c|c|c|c|}
\hline \multirow{2}{*}{ Definitions } & \multicolumn{3}{|c|}{ Source of health insurance } \\
\hline & "Other" $(j=o)$ & off-farm employment $(j=e)$ & All sample \\
\hline \multicolumn{4}{|l|}{ Selection equation, “ $j=o$ ": } \\
\hline \multicolumn{4}{|l|}{ Dependent variable: } \\
\hline Off-farm labor participation $(1 ; 0)$ & 0.33 & & \\
\hline \multicolumn{4}{|l|}{ Explanatory variables: } \\
\hline Potential experience of operator (years) & $33.46^{*}$ & & \\
\hline Race: White $(1 ; 0)$ & 0.83 & & \\
\hline Education: High school $(1 ; 0)$ & 0.42 & & \\
\hline Education: Some college $(1 ; 0)$ & 0.26 & & \\
\hline Education: College and beyond $(1 ; 0)$ & 0.24 & & \\
\hline Operator works full-time off the farm $(1 ; 0)$ & 0.21 & & \\
\hline Farm location: metro $(1 ; 0)$ & 0.37 & & \\
\hline County annual precipitation (Inches) & $43.40^{*}$ & & \\
\hline County average temperature (Fahrenheit) & $42.47^{*}$ & & \\
\hline Unemployment rate (\%) & $5.26^{*}$ & & \\
\hline \multicolumn{4}{|l|}{ Exclusion restriction variables $(1 ; 0)$ : } \\
\hline Household has children under 6 years old $(1 ; 0)$ & 0.10 & & \\
\hline Spouse off-farm labor participation $(1 ; 0)$ & 0.47 & & \\
\hline Unearned income $(\$ 1000)$ & $23.95^{*}$ & & \\
\hline Dairy $(1 ; 0)$ & 0.05 & & \\
\hline Sample size & 8595 & 2201 & 10,796 \\
\hline Number of farms (expanded) & 839,519 & 417,557 & $1,257,076$ \\
\hline
\end{tabular}

Outcome equation, “ $j=o$ " and " $j=e$ ":

Dependent variable:

Off-farm wage rate per hour, average $(\$)^{2}$ :

$$
P 50 \text {, median }(\$)^{3}
$$

$\begin{array}{ccc}32.74^{*, s} & 37.05^{*} & 35.34^{*} \\ 24.86 & 27.84 & 27.50 \\ 68.75 & 64.29 & 68.75 \\ 8.39 & 15.00 & 11.90 \\ & & \\ 31.72^{\star} & 31.74^{\star} & 31.73^{*} \\ 0.93 & 0.96 & 0.95 \\ 0.36 & 0.33 & 0.34 \\ 0.27 & 0.30 & 0.29 \\ 0.29 & 0.36 & 0.33 \\ 0.64 & 0.84 & 0.76 \\ 0.41 & 0.44 & 0.42 \\ 45.31^{*} & 46.76^{*} & 46.18^{*} \\ 43.12^{*, s} & 44.08^{\star} & 43.70^{*} \\ 5.24^{*} & 5.35^{*} & 5.31^{*} \\ 1899 & 2201 & 4100 \\ 274,989 & 417,557 & 692,546\end{array}$

$P 90$, value at the $90^{\text {th }}$ percentile of the distribution (\$)

$P 10$, value at the $10^{\text {th }}$ percentile of the distribution (\$)

Explanatory variables:

Potential experience of operator (years)

Race: White $(1 ; 0)$

Education: High school $(1 ; 0)$

Education: Some college $(1 ; 0)$

Education: College and beyond $(1 ; 0)$

Works full-time off the farm $(1 ; 0)$

Farm location: metro $(1 ; 0)$

County annual precipitation (Inches)

County average temperature (Fahrenheit)

Unemployment rate (\%)

Sample size

Number of farms (expanded) 

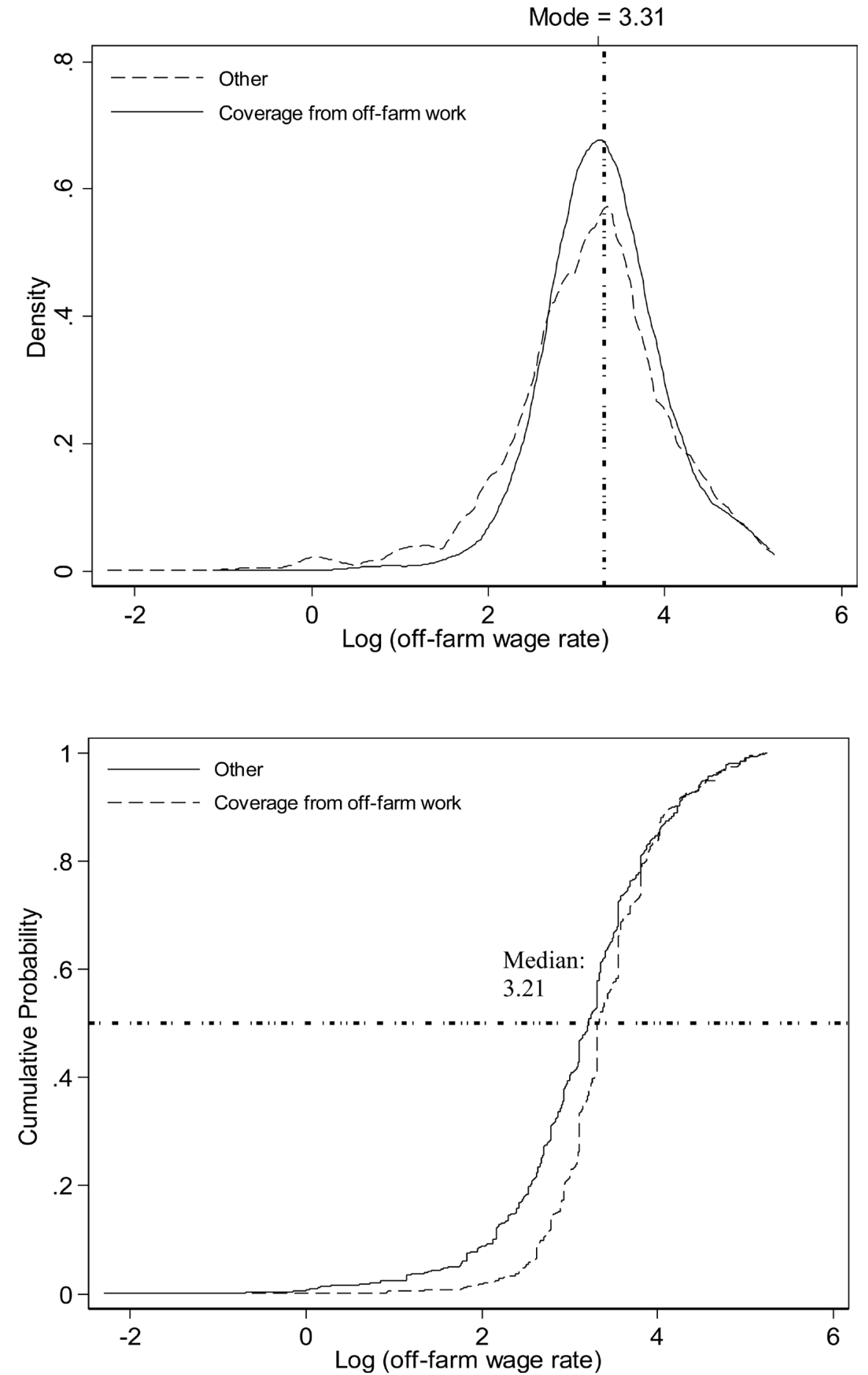

Figure 1. Kernel and empirical cumulative densities of (log) hourly off-farm wages by source of health insurance coverage, 2015 .

density functions for the log off-farm wage distributions among farm operators in the " $o$ " and " $e$ " categories. The panel highlights the significantly advantageous off-farm wage levels of those farm operators in the " $e$ " group who are located in the lower 50-percent portion of the wage distribution.

To address the issue of self-selection with regard to farm operators working 
off the farm when health insurance is purchased from "other" than from an off-farm employer, a central focus is whether the distributional assumption of the normality of the distribution of error terms required in the probit regression estimation of (8) holds. Result of a Jarque-Bera test of normality based on estimating a Generalized Linear Model of off-farm labor participation with a probit link function [49] indicated a rejection of this assumption $\left[\chi^{2}(2)=1.375\right.$ ( $p$-value $=0.0001)]$; a finding that was confirmed from visualizing the distribution of the error terms using a quantile-by-quantile plot. This result gives support to the suggested use of the series-based $S N P$ estimator as described in Equation (8).

To test and/or to correct for the possibility that the binary variable $x_{j i}$ depicting the full-time off-farm work status of the farm operator is endogenous in the $f^{\text {th }}$ off-farm wage equation in (1), a vector of generalized residuals $\hat{v}_{j i}$ was obtained from fitting a probit regression model of this variable using a maximum likelihood procedure. ${ }^{14}$

The result of testing the null hypothesis $\left(\mathrm{H}_{0}\right)$ of weak identification using the empirical Wald $F$ statistic in the $j=$ " $O$ " probit regression indicates a rejection of $H_{0}[$ i.e., $F(3,8581)=58.79$, $(p$-value $=0.00)]$. The finding thus shows that the excluded instruments are jointly significant and hence, they are noted as "non-weak" due to their correlation with $x_{j i}$ [51]. A test based on Hansen's $J$-statistic of over-identifying restriction which examines whether the excluded instruments in the category $j=$ " $o$ " are appropriately independent of the error process is performed [52], and the null hypothesis that the over-identifying restrictions are valid, based on $\chi^{2}(2)=4.188 \quad(p$-value $=0.1232)$, is not rejected (see [53]). A similar result is reached for the probit regression in the category $j=$ " $e$ " where the null hypothesis $\mathrm{H}_{0}$ of weak identification is rejected $[F(5,2185)=$ 4.97 , $(p$-value $=0.00)]$. The assumption that the over-identifying restrictions of the five instruments used are valid is not rejected based on the estimated value of the Hansen's $J$-statistic [ $\chi^{2}(4)=6.194 \quad(p$-value $=0.1851)$ ], a finding comparable to the one reached in the category $j=$ " $o$ ". ${ }^{15}$

One last diagnostic check was performed with regard to the constancy of the variances of the regression residuals in both of the " $e$ " and " $o$ " off-farm wage models. Based on the estimated values of Breusch-Pagan/Cook-Weisberg test for

\footnotetext{
${ }^{14}$ Consistent regression estimates in the probit regression model when testing and/or correcting for endogeneity using the $I V$ procedure requires the distributional assumption of normality to hold [50], particularly when the elements of the vectors of explanatory variables in both the probit and in the outcome equations are the same. In order to insure identification in each of the full-time offfarm work probit models, a set of "exclusion restriction" variables is imposed (see footnote 12) where additional variables were included in each of the " $o$ " and " $e$ " probit equations but not in the corresponding off-farm wage models.

${ }^{15}$ The results from the two stage procedure in both the " $o$ " and " $e$ " categories used to test and/or correct for the endogeneity of "full-time" off-farm work involved a Generalized Method of the Moment (GMM) estimator in the first stage and an OLS regression in the second stage using STATA's ivreg2 procedure (see [53]). Results of both stages of the two-step feasible GMM estimation which allowed for the derivation of generalized residuals $\hat{v}_{j i}$, while not shown in the paper to save on space, they nevertheless can be provided by the author upon request.
} 
heteroscedasticity $\left[\chi^{2}(1)=30.03 \quad(p\right.$-value $=0.000) ; \chi^{2}(1)=65.05 \quad(p$-value $=0.000)]$, respectively], the constant variance assumption is rejected in both models. Accordingly, the robust variance estimator for cluster-correlated data by [44] was used in the analysis.

Use of likelihood ratio test allowed for the rejection of the assumption by the probit model of the normality of the errors, which in effect demonstrates the advantage of using the $S N P$-based single-index $g\left(S^{\prime} \gamma\right)$, with a value of $M=15$, in the derivation of the inverse Mills series of terms as described in (11) in order to correct for sample-selection resulting from off-farm work in category " $o$ ". ${ }^{16}$

Table 2 presents the results of estimating the $\log (w)$ equation for different value of quantiles $(5,10,25,50,75,90$, and 95) for the " $o$ " and " $e$ " categories of sources of health insurance coverage, thus providing an account of all of its conditional distribution. Starting with the " $o$ " category where both the issues of the endogenous "full-time" work variable and self-selectivity of the decision of working off-farm are addressed, findings indicate an increase, although at a decreasing rate, in the rates of return to experience. But interestingly, such an increase in the rates of return to experience seems to benefit farm operators with higher off-farm wages who are in the $50^{\text {th }}-75^{\text {th }}$ percentile range of the off-farm wage distribution. Similarly, the returns to a college education and beyond are not only higher, but they are also statistically significant for farm operators who are better paid and who are in the $50^{\text {th }}-75^{\text {th }}$ percentile range and at the $95^{\text {th }}$ percentile of the off-farm wage distribution. For farm operators in metro counties who are at the $50^{\text {th }}$ percentile of the wage distribution, off-farm wages tend to be lower by $14 \%$ than the wages earned by farm operators in non-metro counties. ${ }^{17}$ A rise in the county's unemployment rate is found to adversely impact the off-farm wages for those farm operators who purchase health insurance from sources "other" than an off-farm employer; particularly if they are located at the $5^{\text {th }}$ percentile, and to a slightly lesser extent, if they are at the $10^{\text {th }}$ percentile of the off-farm wage distribution. The adverse impact of unemployment on off-farm wages for farm households in this category of health insurance is minimal if these households are located at the middle or at the third quartile of the off-farm wage distribution.

Findings further show that those farm operators working full-time and whose health insurance is purchased through sources other than from an "off-farm"

\footnotetext{
${ }^{16}$ Although the results of the probit and $S N P$ regressions are not presented in the paper to save on space, they nevertheless can be provided from the author upon request. The value of the likelihood ratio test between the two models is $2717\left[2^{*}\left(1 l_{\text {probit }}-1 l_{S N P)}\right)\right]$, which is significantly much larger than the corresponding critical value of $\chi^{2}(2)=9.210 \quad(p$-value $=0.01)$. Accordingly, the restrictive probit is rejected demonstrably in favor of the more flexible $S N P$. The selection of $M=15$ of the Hermite polynomial among other values of $K$ that were considered (i.e., 3; 4; 5; and 6) was done based on both a visual inspection of the resulting plots of the densities and since it had the lowest computed Bayesian Information Criterion (BIC). BIC is defined as: $-2^{\star} \log$ Likelihood $+K^{\star} \log (\mathrm{n})$. The $S N P$ regression model is estimated using STATA's snp routine (see [45]).

${ }^{17}$ Since the coefficients of the $\log (w)$ model are in relative terms, the coefficient of a "metro-county" farm location dummy variable at the $50^{\text {th }}$ percentile translates to a $14.45 \%$ (i.e., by $100^{*}\left[\mathrm{e}^{-0.1350}-1\right]$ ) reduction in wages.
} 
Table 2. Summary statistics of variables used in the weighted regression models: 2015.

\begin{tabular}{|c|c|c|c|c|c|c|c|}
\hline & \multicolumn{7}{|c|}{$J^{\text {th }}$ category “o": $\log (w)$} \\
\hline & \multicolumn{7}{|c|}{ "Other" than from operator's off-farm work } \\
\hline & $5^{\text {th }}$ Centile & $10^{\text {th }}$ Centile & $25^{\text {th }}$ Centile & $50^{\text {th }}$ Centile & $75^{\text {th }}$ Centile & $90^{\text {th }}$ Centile & $95^{\text {th }}$ Centile \\
\hline Constant & -1.1585 & -0.5637 & 1.1095 & $0.8848^{* * *}$ & $1.0528^{*}$ & $1.4352^{* *}$ & 1.3215 \\
\hline Experience of operator & -0.0128 & 0.0055 & 0.0253 & $0.0437^{\star *}$ & $0.0353^{\star *}$ & 0.0010 & -0.0114 \\
\hline Experience, squared & 0.0004 & -0.0001 & -0.0002 & $-0.0007^{\star \star}$ & $-0.0006^{* *}$ & -0.0001 & 0.0002 \\
\hline Race: White & -0.9568 & -0.6965 & -0.1916 & 0.2108 & $0.5256^{* *}$ & $0.7809^{* *}$ & 0.7780 \\
\hline High school Education & 0.0823 & -0.1483 & -0.1779 & -0.1215 & $-0.2981^{\star *}$ & -0.1256 & 0.0128 \\
\hline Some college & -0.0945 & -0.3636 & -0.2043 & -0.0603 & $-0.2555^{\star}$ & -0.0407 & 0.0289 \\
\hline College and beyond & 0.1255 & -0.0945 & 0.1018 & $0.3488^{* * *}$ & $0.3520^{* *}$ & 0.4550 & $0.5948^{\star *}$ \\
\hline Off-farm work: full-time & $2.7828^{* *}$ & $1.7411^{\star * *}$ & $0.9962^{\star * \star}$ & 0.0129 & $-0.2595^{\star}$ & $-0.7069^{* *}$ & $-0.8368^{* * *}$ \\
\hline Farm location: metro & -0.1548 & -0.0807 & -0.0643 & $0.1350^{* *}$ & 0.0177 & 0.0541 & -0.0383 \\
\hline Precipitation & -0.0052 & -0.0007 & -0.0054 & -0.0020 & $-0.0035^{\star *}$ & -0.0031 & 0.0020 \\
\hline Temperature & 0.0169 & 0.0119 & $0.0194^{\star * *}$ & $0.0147^{\star \star *}$ & $0.0227^{\star * \star}$ & $0.0209^{* * *}$ & $0.0241^{\star \star}$ \\
\hline Unemployment & $-0.1640^{* * *}$ & $-0.1562^{* * *}$ & -0.0424 & $-0.0449^{* * *}$ & $-0.0092^{*}$ & 0.0048 & -0.0149 \\
\hline Generalized residual & $-1.5825^{\star *}$ & $-0.9706^{\star * *}$ & $-0.4548^{\star * *}$ & 0.0555 & -0.0280 & 0.1629 & 0.1509 \\
\hline IMR & 9.8815 & 8.7002 & 2.4521 & $2.7348^{\star * \star}$ & 2.2346 & $2.3412^{\star *}$ & $2.6224^{\star * *}$ \\
\hline $\mathrm{IMR}^{2}$ & -8.6920 & -7.1334 & -2.7001 & -2.2699 & -1.3745 & -1.1705 & -0.9775 \\
\hline $\mathrm{IMR}^{3}$ & 2.1420 & 1.7097 & 0.7669 & 0.5851 & 0.3338 & 0.2446 & 0.1366 \\
\hline \multirow[t]{2}{*}{ Pseudo $\mathrm{R}^{2}$} & 0.1956 & 0.1225 & 0.0602 & 0.0700 & 0.1125 & 0.1279 & 0.1294 \\
\hline & \multicolumn{7}{|c|}{$J^{\text {th }}$ category "e": Operator's off-farm work } \\
\hline Constant & -0.0035 & $1.3748^{*}$ & $1.8979^{* * *}$ & $3.6611^{\star * *}$ & $3.4126^{* * *}$ & $3.4345^{* * *}$ & $3.0381^{* * *}$ \\
\hline Experience of operator & -0.0064 & -0.0010 & -0.0102 & 0.0150 & 0.0090 & 0.0126 & $0.0207^{*}$ \\
\hline Experience, squared & 0.0002 & 0.0001 & 0.0003 & -0.0002 & -0.0002 & -0.0001 & -0.0002 \\
\hline Race: White & 0.1622 & 0.1390 & $0.2211^{* *}$ & -0.1238 & -0.1380 & $-0.3207^{\star * *}$ & -0.1039 \\
\hline High school Education & 0.0850 & 0.1388 & $0.2186^{*}$ & 0.0139 & 0.1524 & 0.0061 & 0.2272 \\
\hline Some college & 0.3087 & 0.2203 & $0.3127^{* *}$ & 0.1616 & 0.3414 & 0.2007 & 0.3499 \\
\hline College and beyond & 0.5216 & $0.5194^{* * *}$ & $0.6063^{* * *}$ & $0.4955^{* * *}$ & 0.6928 & $0.6179^{* * *}$ & 0.7227 \\
\hline Off-farm work: full-time & 1.78450 & 0.8800 & 0.4723 & $-0.7379^{\star}$ & $-0.3506^{\star}$ & -0.0852 & -0.0723 \\
\hline Farm location: metro & $0.2347^{* * *}$ & $0.1636^{* * *}$ & $0.1547^{\star * *}$ & $0.0723^{*}$ & $0.1042^{\star *}$ & $0.2441^{\star * *}$ & $0.2111^{\star * *}$ \\
\hline Precipitation & 0.0018 & -0.0029 & $-0.0076^{* * *}$ & $-0.0035^{\star *}$ & $-0.0038^{*}$ & -0.0016 & $-0.0049^{\star * *}$ \\
\hline Temperature & 0.0096 & 0.0037 & $0.0105^{* *}$ & $0.0075^{\star *}$ & $0.0095^{* *}$ & $0.0126^{*}$ & $0.0183^{* * *}$ \\
\hline Unemployment rate & 0.0272 & 0.0089 & 0.0039 & $-0.0238^{\star}$ & -0.0079 & -0.0166 & -0.0183 \\
\hline Generalized residual & 0.8370 & -0.3525 & -0.2910 & 0.2702 & -0.0981 & -0.3197 & -0.3192 \\
\hline Pseudo $\mathrm{R}^{2}$ & 0.0495 & 0.0613 & 0.0626 & 0.1024 & 0.1580 & 0.1993 & 0.2188 \\
\hline
\end{tabular}

${ }^{1}$ Note: Statistical significance is based on standard errors that were computed based on 1000 bootstrapped replicate samples. Because of the large sample size, $K$ is allowed to grow until the coefficients of IMR at all of the quantiles considered consistently did not exhibit statistical significance at two levels in a row (i.e., $K=3$; see Equation (10)). ${ }^{*}, * *, * *$ Significance at the $10 \%, 5 \%$, and $1 \%$ levels, respectively. Pseudo $R^{2}=1-\frac{V_{\tau}^{f}}{V_{\tau}^{r}}$, where $V_{\tau}^{f}$ is the sum of the weighted distances for the full quantile regression model [see Equation (14)], and $V_{\tau}^{r}$ is the sum of the weighted distances for the restricted model that includes only the intercept (for more detail, see [54]; pp. 51-52). 
employer, are rewarded with higher wages; although decreasingly, only if their wages are in the lower quartile portion of the off-farm wage distribution. In contrast, farm operators who are paid the highest (at the $75^{\text {th }}, 90^{\text {th }}$, and $95^{\text {th }}$ percentiles) while maintaining full-time off-farm employment, relative to those operators with part-time employment, seem to face discounted off-farm wages (by $23 \%, 51 \%$, and $57 \%$, respectively). ${ }^{18}$ The result of an increasingly reduced offfarm wages as farm operators who are in this category step up in the off-farm wage distribution from the $75^{\text {th }}$ percentile to the $95^{\text {th }}$ percentile, although is perhaps due to the wage-benefit tradeoff, is probably picking up the impact of an employment benefits package that may include benefits other than those that are attributed to the provision by an employer of health care coverage [23].

The lower part of Table 2 presents the conditional quantile regression results of the $\log (w)$ model for farm operators with health insurance coverage provided by their employers. While the rates of return to experience of farm operators are positive for the top half of the off-farm wage distribution, such returns are positive and statistically significant only at the $95^{\text {th }}$ percentile. A positive and statistically significant impact of "college and beyond" education on off-farm wages is found for farm operators at the $10^{\text {th }}, 25^{\text {th }}, 50^{\text {th }}$, and $90^{\text {th }}$ percentiles of the off-farm wage distribution. An interesting result concerning the role of education in impacting off-farm wages is the successively higher rates of return to education noted across all of the percentiles considered as the level of educational achievement by the farm operator rises; particularly when the extra schooling involves a college degree. Most notable is the "sheepskin" effect in the returns to education found at the $25^{\text {th }}$ percentile where operators with consecutively higher educational credentials are shown to command statistically significant higher levels of off-farm wages. ${ }^{19} \mathrm{~A}$ farm location in a metro county appears to benefit all farm operators across all of the percentiles considered, particularly at the $5^{\text {th }}$ and the $90^{\text {th }}$ and the $95^{\text {th }}$ percentiles. Results show that farmers in the category where health insurance coverage is obtained from an "off-farm" employer are largely immune to a weakening in the off-farm labor market as a rise in unemployment seems to adversely impact the off-farm wages, although mildly, of only farm operators located at the $50^{\text {th }}$ percentile of the off-farm wage distribution.

Off-farm wages for farm operators who work "full-time" off the farm, in comparison to those who work "part-time", are statistically different only for those farmers at the $50^{\text {th }}$ and $75^{\text {th }}$ percentiles of the off-farm wage distribution. ${ }^{20}$ Specifically, farm operators with "full-time" off farm employment at the $50^{\text {th }}$ and $75^{\text {th }}$ percentile of the off-farm wage distribution, are faced with, respectively,

\footnotetext{
${ }^{18}$ The coefficient of "Full-time" off-farm work dummy variable at the $75^{\text {th }}$ percentile indicates a $23 \%$ (i.e., by $100 *\left[\mathrm{e}^{-0.2595}-1\right]$ ) decrease in off-farm wages. The corresponding coefficients at the $90^{\text {th }}$ and $95^{\text {th }}$ percentiles are converted to percent reductions in similar fashion.

${ }^{19}$ The "sheepskin" effect extensively debated by labor economists contends that, as noted by [47], "wages will rise faster with extra years of education when the extra year also conveys a certificate." ${ }^{20}$ The exogeneity assumption of the "Full-time" off-farm dummy variable is not rejected for the log $(w)$ model at all of the percentiles considered based on statistically insignificant coefficients of the generalized residual described in Equation (11).
} 
$52 \%$ and $30 \%$ reduction in their off-farm wages (see [22]). Findings also show, based on the levels of estimated coefficients, that farm operators with "full-time" off farm employment across the off-farm wage distributions are faced with a larger drop in their off-farm wages across all of the percentiles considered if their health insurance coverage is provided through their "off-farm" employer rather from "other sources". These results of discounted off-farm wages at the $50^{\text {th }}$ and $75^{\text {th }}$ percentiles of the off-farm wage distribution for farmers with "full-time" off-farm employment and who have health insurance coverage through their "off-farm" employer, and especially those results of the larger drop in off-farm wages for farmers across all the percentiles relative to when health insurance coverage is obtained from other sources, are consistent with the notion of compensating differential as prescribed to in the compensating wage theory. ${ }^{21}$

\section{Conclusions}

Data from the 2015 Agricultural Resource Management Survey and quantile regression were used to discern the effect of working "full-time" off the farm and of "other" factors on the hourly off-farm wage rates among U.S. farm operators. The specific groups of targeted operators were those with an "employer-provided" health insurance coverage, and those with health insurance coverage obtained from "other" sources.

This research finds, based on the use of a quantile regression procedure to estimate a "Mincerian" wage equation, a statistically negative association between "full-time" off-farm work and off-farm wages, but only for those operators in both categories of health insurance coverage who are already located in the higher portions of their respective off-farm wage distributions. While the result that alludes to a trade-off between off-farm wages and health insurance for farmers who work "full-time" off the farm regardless to whether health insurance is provided by an off-farm employer or from other sources is in accordance with what the compensating wage theory predicts, it is prudent to point out that not all of the reduction in the off-farm wage rate can be relegated to health insurance coverage. However, the suggestion of a possible trade-off between off-farm wages and health insurance at the upper quantiles of the off-farm wage distribution is timely as it might inform the current healthcare debate among policymakers

\footnotetext{
${ }^{21}$ However, and because the off-farm wage model used does not control for other benefits that are part of an employer's compensation package (e.g., bonuses, $401 \mathrm{~K}$ matching contributions, reimbursement for continuing education, life insurance, etc.) due to lack of such data in the ARMS, it is hard to assert with certainty that the full amount of the discount in wages is due to the health insurance coverage that the farmer obtains for the employer. Accordingly, all the levels of the discount in off-farm wages reported to imply the presence of compensating differential should be viewed as upper bounds to these differentials. Yet another caveat to be noted is that a Wald-test to discern whether the differences in the coefficients are statistically significant across the two models based on the source of health insurance when farmers worked "full-time" off their farms and across all the percentiles considered was not conducted. This was due to the complexity of the estimation that would have resulted particularly when the specified SNP-based single index $\mathrm{g}($.) was set at 15 and when the standard errors of estimated coefficients were measured based on 1000 replicate samples.
} 
concerning the "ultimate" bearer of the cost of healthcare when a firm, with farm operators constituting part of its labor force, offers health insurance to its core of "full-time" employees.

Findings further demonstrate the importance of operator's work experience in positively impacting off-farm wages among those operators who are already in the higher spectrum of the off-farm wage distribution. This is particularly true in the case of those operators where health insurance is provided by the "off-farm" employer whereby the reward to experience was only for those in off-farm jobs that pay the highest wages.

Farm operators with a college education and whose health insurance is obtained from sources "other" than from an "off-farm" employer are found with higher returns to schooling if their off-farm wages are in the two quantiles above the middle of the off-farm wage distribution. The fact that not all of these college-educated farmers across the off-farm wage distribution are shown to benefit from higher returns to their higher education may be related to the type of off-farm occupation that was held by these farmers. Findings by [55], which may help in explaining the lackluster off-farm wage premium for this group of farmers, point to a flattening in the growth of the wage gap that was witnessed in the U.S. between 2010 and 2015 between workers with a college or graduate degree and those with only a high school. Valletta [55] attributes this lack of growth in higher educational returns to two factors. The first of these factors is "polarization", which is interpreted as a shift away from middle-skilled careers driven mainly by technological change. The second cause is "skill downgrading", which is construed as a general weakening in the demand for advanced cognitive skills. In contrast, farm operators whose health insurance is provided by an "employer" seem to benefit the most from having a college education as the educational impact on off-farm wages seems to have higher wage premia across all of the off-farm wage quantiles with the exception of the lowest and highest quantiles. In that farmers in this category who benefit from the higher educational returns may be explained by both the level of their higher education and the type of occupation that they hold. Valletta [55] notes that the higher education wage premium, which may be relevant to farmers in this category of health insurance coverage, results from the rising demand for the most highly educated individuals in careers that require extensive non-routine cognitive skills.

Among the two groups of farmers where health insurance coverage is obtained either from an "off-farm" employer or from "other" sources, college education (i.e., BA, BS, and graduate degrees) is identified as the one covariate with the potential of widening the off-farm wage gap among those in the lower two quantiles of wage distributions. A similar conclusion was reached by [56], who noted that investments on education may contribute to an increase in the inequality between the lower part of the wage distribution up to roughly close to the median. A study by [57] pointed to some possible reasons for obtaining a positive relationship between returns of education and higher wage quantiles. 
One of these reasons is the possibility that over-education in low paid jobs may lead to rather low returns to education in the left-hand tail of the wage distribution. Another reason may be related to the "ability" of the individual, which is thought to be increasing with higher wage levels with its attendant impact in magnifying the returns of education in the right-hand tail of the wage distribution. If any of these reasons hold true in explaining the lower returns to education for farmers in the lower portions of the off-farm wage distributions, this suggests that investments in specialized "skill-increasing" education tailored to high paid jobs in rural areas are needed to help stem disparity in the off-farm wage distribution.

\section{Acknowledgements}

The author is grateful to Ryan Williams (ERS, USDA) for the climate data he provided for this research.

\section{References}

[1] White, T.K. and Hoppe, R.A. (2012) Changing Farm Structure and the Distribution of Farm Payments and Federal Crop Insurance. U.S. Department of Agriculture, Economic Research Service, EIB-91.

[2] Ollinger, M., MacDonald, J. and Madison, M. (2005) Technological Change and Scale Economies in the Poultry Industry. American Journal of Agricultural Economics, 87, 116-129. https://doi.org/10.1111/j.0002-9092.2005.00706.x

[3] Mishra, A.K., El-Osta, H.S., Morehart, M.J., Johnson, J.D. and Hopkins, J.W. (2002) Income, Wealth, and the Economic Well-Being of Farm Households. U.S. Department of Agriculture, Washington DC, AER-812.

[4] Ahearn, M. (1986) Financial Well-Being of Farm Operators and Their Households. U.S. Department of Agriculture, Washington DC, AER 563.

[5] El-Osta, H.S., Mishra, A.K. and Morehart, M.J. (2008) Farm Labor Participation Decisions of Married Farm Couples and the Role of Government Payments. Review of Agricultural Economics, 30, 311-332. https://doi.org/10.1111/j.1467-9353.2008.00406.x

[6] Lettau, M.K. (1994) Compensation in Part-Time Jobs versus Full-Time Jobs: What if the Job Is the Same? U.S. Department of Labor, Bureau of Labor Statistics, Working Paper 260.

[7] Nardone, T.J. (1986) Part-Time Workers: Who Are They? A New Definition of Part-Timers, Utilizing Existing Data, from the Current Population Survey, Gives a More Accurate Estimate of the Number of Part-Time Workers. Monthly Labor Review February, 13-19.

[8] Mishra, A.K. and Goodwin, B.K. (1997) Farm Income Variability and the Off-Farm Labor Supply. American Journal of Agricultural Economics, 79, 880-887. https://doi.org/10.2307/1244429

[9] Brown, J.P. and Weber, J.G. (2013) The Off-Farm Occupations of U.S. Farm Operators and Their Spouses. U.S. Department of Agriculture, Washington DC, EIB 117.

[10] Jensen, H.H. and Salant, P. (1985) The Role of Fringe Benefits in Operator Off-farm Labor Supply. American Journal of Agricultural Economics, 67, 1095-1099.

https://doi.org/10.2307/1241379 
[11] D'Antoni, J.M., Mishra, A.K. and Khanal, A.R. (2014) Effect of Health Insurance Coverage on Labor Allocation: Evidence from US Farm Households. Health Economics Review, 4, 1-11. https://doi.org/10.1186/s13561-014-0019-1

[12] Rosen, S. (1986) The Theory of Equalizing Differences. In: Ashenfelter, O.C. and Layard, R., Eds., The Handbook of Labor Economics, Vol. 1, North-Holand, Amsterdam, 641-692.

[13] Ahearn, M.C., Williamson, J.M. and Black, N. (2014) Implications of Health Care Reform for Farm Businesses and Families. Applied Economic Perspectives and Policy, 36, 1-27.

[14] Dillender, M.O., Heinrich, C.J. and Houseman, S.N. (2016) Health Insurance Reform and Part-Time Work: Evidence from Massachusetts. Labour Economics, 43, 151-158.

[15] Riportella, R. and O’Neill, B. (2015) You and Health Insurance: Making a Smart Choice for Farm Families. Journal of Extension, 53, 1-4.

[16] Koenker, R. and Bassett, G. (978) Regression Quantiles. Econometrica, 46, 33-50. https://doi.org/10.2307/1913643

[17] Leibowitz, A. (1983) Fringe Benefits in Employee Compensation. In: Triplett, J.E., Ed., The Measurement of Labor Cost, The University of Chicago Press, Chicago, 371-394.

[18] French, M.T. and Kendall, D.L. (1992) The Value of Job Safety for Railroad Workers. Journal of Risk and Uncertainty, 5, 175-185. https://doi.org/10.1007/BF00057570

[19] Lehrer, S.F. and Pereira, N.S. (2007) Worker Sorting, Compensating Differentials and Health Insurance: Evidence from Displaced Workers. Journal of Health Economics, 26, 1034-1056.

[20] Monheit, A., Hagan, M., Berk, M. and Farley, P. (1985) The Employed Uninsured and the Role of Public Policy. Inquiry, 22, 348-364.

[21] Gruber, J. (2000) Health Insurance and the Labor Market. In: Culyer, A.J. and Newhouse, J.P., Eds., Handbook of Health Economics, Vol. 1, Part A, Elsevier, New York, 645-706.

[22] Olson, C. (2002) Do Workers Accept Lower Wages in Exchange for Health Benefits? Journal of Labor Economics, 20, S91-S114. https://doi.org/10.1086/338675

[23] Goldman, D., Sood, N. and Leibowitz, A. (2005) Wage and Benefit Changes in Response to Rising Health Insurance Costs. Working Paper 11063, National Bureau of Economic Research, Cambridge. http://www.nber.org/papers/w11063 https://doi.org/10.3386/w11063

[24] Mishra, K.A., El-Osta, H.S. and Ahearn, M.C. (2012) Health Care Expenditures of Self-Employed Farm Households in the United States. Agricultural Economics, 43, 75-88. https://doi.org/10.1111/j.1574-0862.2011.00566.x

[25] Sastre, M. and Ayala, L. (2002) Europe vs. the United States: Is There a Trade-Off between Mobility and Inequality? ISER Working Papers Number 2002-26.

[26] Duraisamy, M. and Duraisamy, P. (2016) Gender Wage Gap across the Wage Distribution in Different Segments of the Indian Labour Market, 1983-2012: Exploring the Glass Ceiling or Sticky Floor Phenomenon. Applied Economics, 48, 4098-4111. https://doi.org/10.1080/00036846.2016.1150955

[27] Mincer, J. (1994) Schooling, Experience, and Earnings. Human Behavior and Social Institutions, 2, National Bureau of Economic Research.

[28] Huffman, W.E. and Lange, M.D. (1989) Off-Farm Work Decisions of Husbands and 
Wives: Joint Decision Making. The Review of Economics and Statistics, 71, 471-480. https://doi.org/10.2307/1926904

[29] Heckman, J. (1979) Sample Selection as a Specification Error. Econometrica, 47, 153-161. https://doi.org/10.2307/1912352

[30] Dubin, J.A. and Rivers, D. (1989) Selection in Linear Regression, Logit, and Probit Models. Sociological Methods and Research, 18, 360-390. https://doi.org/10.1177/0049124189018002006

[31] Buchinsky, M. (1998) The Dynamics of Changes in the Female Wage Distribution in the USA: A Quantile Regression Approach. Journal of Applied Econometrics, 13, 1-30. https://doi.org/10.1002/(SICI)1099-1255(199801/02)13:1<1::AID-JAE474>3.0.CO;2A

[32] Buchinsky, M. (2001) Quantile Regression with Sample Selection: Estimating Women's Returns to Education in the U.S. Empirical Economics, 26, 87-113. https://doi.org/10.1007/s001810000061

[33] Klein, R. and Spady, R. (1993) An Efficient Semiparametric Estimator of the Binary Response Models. Econometrica, 61, 387-421. https://doi.org/10.2307/2951556

[34] Gabler, S., Laisney, F. and Lechner, M. (1993) Semiparametric Estimation of Binary-Choice Models with an Application to Labor-Force Participation. Journal of Business and Economic Statistics, 11, 61-80.

[35] Phillips, P.C.B. (1983) ERA's: A New Approach to Small Sample Theory. Econometrica, 51, 1505-1525. https://doi.org/10.2307/1912287

[36] Gallant, R. and Nychka, D.W. (1987) Semi-Nonparametric Maximum Likelihood Estimation. Econometrica, 55, 363-390. https://doi.org/10.2307/1913241

[37] Van der Klaauw, B. and Koning, R.H. (2003) Testing the Normality Assumption in the Sample Selection Model with an Application to Travel Demand. Journal of Business and Economic Statistics, 21, 31-42. https://doi.org/10.1198/073500102288618739

[38] Albrecht, J., van Vauuren, A. and Vroman, S. (2009) Counterfactual Distribution with Sample Selection Adjustment: Econometric Theory and an Application to the Netherland. Labour Economics, 16, 383-396.

[39] Newey, W. (2009) Two-Step Series Estimation of Sample Selection Models. Econometrics Journal, 12, S217-S229. https://doi.org/10.1111/j.1368-423X.2008.00263.x

[40] Dustmann, C. and Meghir, C. (2005) Wages, Experience and Seniority. Review of Economic Studies, 72, 77-108. https://doi.org/10.1111/0034-6527.00325

[41] Vella, F. (1992) Simple Tests for Sample Selection Bias in Censored and Discrete Choice Models. Journal of Applied Econometrics, 7, 413-421. https://doi.org/10.1002/jae.3950070407

[42] Gourieroux, C., Monfort, A., Renault, E. and Trognon, A. (1987) Generalized Residuals. Journal of Econometrics, 34, 5-32.

[43] Terza, J.V., Basu, A. and Rathouz, P.J. (2008) Two-Stage Residual Inclusion Estimation: Addressing Endogeneity in Health Econometric Modeling. Journal of Health Economics, 27, 531-543.

[44] Huber, P.J. (1967) The Behavior of Maximum Likelihood Estimates under Nonstandard Conditions. In: Proceedings of the 5 th Berkeley Symposium on Mathematical Statistics and Probability, University of California Press, Berkeley, Vol. 1, 221-223.

[45] Dubman, R.W. (2000) Variance Estimation with USDA's Farm Costs and Returns 
Surveys and Agricultural Resource Management Study Surveys. ERS Staff Paper, U.S. Department of Agriculture, Economic Research Service, AGES 00-01.

[46] De Luca, G. (2008) SNP and SML Estimation of Univariate and Bivariate Binary-Choice Models. The Stata Journal, 8, 190-220.

[47] Hungerford, T. and Solon, G.S. (1987) Sheepskin Effects in the Returns to Education. The Review of Economics and Statistics, 69, 175-177. https://doi.org/10.2307/1937919

[48] Huffman, W.E. and El-Osta, H.S. (1997) Off-Farm Work Participation, Off-Farm Labor Supply and On-Farm Labor Demand of U.S. Farm Operators. Dept. Econ. SP-290, Iowa State University.

[49] Jarque, C.M. and Bera, A.K. (1980) Efficient Tests for Normality, Homoscedasticity and Serial Independence of Regression Residuals. Economics Letters, 6, 255-259.

[50] Vella, F. and Verbeek, M. (1999) Estimating and Interpreting Models with Endogenous Treatment effects. Journal of Business and Economic Statistics, 7, 473-478.

[51] Stock, J.H., Wright, J.H. and Yogo, M. (2002) A Survey of Weak Instruments and Weak Identification in Generalized Method of Moments. Journal of Business and Economic Statistics, 20, 518-529. https://doi.org/10.1198/073500102288618658

[52] Hansen, L. (1982) Large Sample Properties of Generalized Method of Moments Estimators. Econometrica, 50, 1029-1054. https://doi.org/10.2307/1912775

[53] Baum, C.F., Schaffer, M.E. and Stillman, S. (2007) Enhanced Routines for Instrumental Variables/Generalized Method of Moments Estimation and Testing. The Stata Journal, 7, 465-506.

[54] Hao, L.D. and Naiman, Q. (2007) Quantile Regression. Sage Publications, Inc., Thousand Oaks. https://doi.org/10.4135/9781412985550

[55] Valletta, R.G. (2016) Recent Flattening in the Higher Education Wage Premium: Polarization, Skill Downgrading, or Both? Federal Reserve Bank of San Francisco, Working Paper 2016-17.

[56] Sequeira, T.N. and Santos, M. (2015) Labour Market Returns and Wage Inequality: New Evidence for Europe. Research in Applied Economics, 7, 31-45. https://doi.org/10.5296/rae.v7i3.8020

[57] Martins, P.S. and Pereira, P.T. (2004) Does Education Reduce Wage Inequality? Quantile Regression Evidence from 16 Countries. Labour Economics, 11, 355-371. 